CLINICAL STUDY

\title{
Treatment for 24 months with recombinant human GH has a beneficial effect on bone mineral density in young adults with childhood-onset GH deficiency
}

\author{
G S Conway, M Szarras-Czapnik ${ }^{1}$, K Racz ${ }^{2}$, A Keller ${ }^{3}$, P Chanson ${ }^{4}$, M Tauber ${ }^{5}$, M Zacharin ${ }^{6}$ on behalf of the 1369 \\ GHD to GHDA Transition Study Group \\ Department of Endocrinology and Diabetes, University College London Hospitals, 250 Euston Road, London NW1 2PQ, UK, ${ }^{1}$ Department of \\ Endocrinology, The Children's Memorial Health Institute, Warsaw, Poland, ${ }^{2}$ Department of Medicine, Semmelweis University Budapest, Budapest, \\ Hungary, ${ }^{3}$ Children's Hospital, University of Leipzig, Leipzig, Germany, ${ }^{4}$ Service d'Endocrinologie et des maladies de la Reproduction, Assistance-Publique \\ Hôpitaux de Paris, Hôpital de Bicêtre, and University Paris-Sud, Paris, France, ${ }^{5}$ Unite d'Endocrinologie, Hopital des Enfants, CHU de Toulouse, Toulouse, \\ France and ${ }^{6}$ Department of Endocrinology and Diabetes, Royal Children's Hospital, Parkville, Victoria, Australia \\ (Correspondence should be addressed to G S Conway; Email: g.conway@ucl.ac.uk)
}

\begin{abstract}
Objective: Discontinuation of growth hormone $(\mathrm{GH})$ therapy on completion of linear growth may adversely affect bone mineral density (BMD) in young adults with childhood-onset GH-deficiency (GHD). In the present study, we analyzed the impact of GH treatment on bone in young adults with GHD. Methods: BMD at the lumbar spine (L2-L4), total hip, and total body was measured at baseline and after 24 months in a cohort of young adults (18-25 years; $n=160)$ with severe GHD treated with GH during childhood who were randomized to $\mathrm{GH}(n=109)$ or no treatment $(n=51)$ in a multicenter, multinational, open-label study. GH starting doses ( $0.2 \mathrm{mg} /$ day (males), $0.4 \mathrm{mg} /$ day (females)) were increased after 1 month to $0.6 \mathrm{mg} /$ day (males) and $0.9 \mathrm{mg} /$ day (females) and then to $1.0 \mathrm{mg} / \mathrm{day}$ (males) and $1.4 \mathrm{mg} /$ day (females) at 3 months for the remainder of the study.

Results: After 24 months, lumbar spine BMD had increased significantly more in GH-treated patients than in controls (6 vs $2 \%$; estimated treatment difference; $3.5 \%$ (95\% confidence interval, $1.52-5.51$ ) $P<0.001)$. GH also had a significant positive effect on total hip BMD $(P=0.015)$. Total body BMD was unchanged from baseline $(P=0.315)$.

Conclusions: In young adults treated for childhood-onset GHD, there is a beneficial effect of continued GH treatment on BMD in adult life. Twenty-four months of GH treatment in these young adults was associated with an estimated 3.5\% greater increase in BMD of the lumbar spine compared with controls.
\end{abstract}

European Journal of Endocrinology 160 899-907

\section{Introduction}

Children with GH-deficiency (GHD) (1-3), as well as adult patients with childhood-onset or adult-onset GHD $(1,2,4-8)$, exhibit reduced bone mineral density (BMD) compared with healthy controls. Specifically, in young adults $(<30$ years of age) with childhood-onset GHD, significant reductions in cortical thickness, cortical cross-sectional area, and overall cortical content have been reported, which in association with the smaller bone size, result in a reduced BMD compared with age- and sex-matched healthy controls $(1,2,8,9)$, placing these patients at increased risk of fracture (10). Indeed, clinical studies have shown that the prevalence of fractures is 2.7-3 times higher in adult hypopituitary patients than in age-matched controls $(11,12)$. Data from these studies suggest that the increased risk may be due to GHD rather than to other pituitary hormone deficiencies or their replacement (12).
A role for $\mathrm{GH}$ in the accretion of bone mass is supported by several lines of evidence. First, in vitro studies show that $\mathrm{GH}$ and its major effector, insulin-like growth factor-1 (IGF-1), are both mitogens for osteoblasts $(13,14)$. Second, increases in markers of bone remodeling occur during $\mathrm{GH}$ replacement therapy in adults with GHD (3, 4, 8, 15). Finally, accumulated evidence supports the finding that $\mathrm{GH}$ replacement in children $(3,16)$ and adults with $\operatorname{GHD}(8,17,18)$ improves BMD.

Normally, $\sim 40 \%$ of skeletal mass is accrued during puberty (19), but accumulation of bone mass at various skeletal sites continues for 1-7 years after longitudinal bone growth has stopped $(19,20)$. However, the timing of acquisition of peak bone mass in young adults with GHD is not well researched. In a study of 16 adolescent patients (aged 15-19 years) with isolated GHD, lumbar $\mathrm{BMD}$ area (bone mineral content (BMC) corrected for vertebral surface area) and lumbar BMD volume (BMC 
corrected for vertebral volume) were below the normal mean, and mean values of peak BMD were reduced in patients compared with controls (21). Twenty-four months after cessation of $\mathrm{GH}$ treatment, lumbar bone mass had declined in patients but not in controls. These results suggest that in young adults with GHD, GH replacement may be needed to support adequate bone mass accumulation in order to maintain bone mass in adult life (21-23). Furthermore, it seems likely that adolescents with severe GHD may not have achieved their peak bone mass at adult height, when $\mathrm{GH}$ treatment is often discontinued, and that GH may play an important role in the acquisition and maintenance of bone mass during this particular period of bone consolidation (3, 24-26). In addition to reduced BMD, some adults with childhood-onset GHD also have lower lean body mass, diminished quality of life (QoL), abnormal lipids, and impaired cardiac function compared with older adults with adult-onset GHD $(27,28)$. It is postulated that lack of GH during late teens and early twenties, a period when bone and muscle mass continue to accrue, and somatic development continues and contributes to the deterioration of these parameters in adults with childhood-onset GHD (29). Several studies have yielded evidence to support the efficacy of GH in preventing the adverse changes in body composition $(26,30,31)$. Thus, the practice of discontinuing $\mathrm{GH}$ in all patients after attainment of adult height is under review and it is suggested that continuation of $\mathrm{GH}$ replacement in GHD individuals during the post-pubertal 'transition' phase may alleviate the metabolic complications of $\mathrm{GH}$ deficiency, including maturation of bone $(32,33)$.

The aim of this study was to investigate the efficacy of 24-months' treatment with GH on BMD in young adults with childhood-onset GHD.

\section{Materials and methods}

This was a randomized, controlled, open-label study conducted at 22 sites in 12 countries (Australia, Belgium, UK, France, Germany, Hungary, New Zealand, Norway, Poland, Spain, Sweden, and Switzerland). The study was conducted according to the guidelines of Good Clinical Practice, the Declaration of Helsinki, and with approval from the Ethical Review Boards appropriate for each of the study centers.

The primary objective of the study was to evaluate the effect of 24 months of GH treatment on BMD in young adults with childhood-onset GHD. The effect of GH treatment on markers of bone metabolism, serum IGF-1, IGF-binding protein-3 (IGFBP-3), and safety were also evaluated as secondary endpoints.

Study participants were young adults (18-25 years; body mass index, $18-30 \mathrm{~kg} / \mathrm{m}^{2}$ ) diagnosed with GHD during childhood on the basis of at least one provocative test of GH secretion. All subjects had received GH during childhood until adult height was attained. Subjects with isolated or only two (including $\mathrm{GH}$ ) pituitary hormone deficiencies were required to undergo a further provocative GH test after their 16th birthday to confirm the diagnosis. Subjects with three or more pituitary hormone deficiencies were exempt from further testing. All GH testing was performed in accordance with the consensus guidelines that were present at the time of patient recruitment into the trial (34). Patients were excluded from the study if they had received GH treatment during the month before randomization or if they had experienced severe disease that could interfere with $\mathrm{GH}$ treatment or participation in the study. Other reasons for exclusion included serious cardiac, hepatic or renal disease, uncontrolled hypertension, diabetes, acromegaly, disease that could affect bone metabolism, or any malignant tumor. Female subjects were excluded if pregnant or lactating. For subjects with more than one (other than GH) known deficient hypothalamic-pituitary axis, replacement doses of thyroid, adrenal, gonadal and/or antidiuretic hormone were to have been unchanged for at least 6 months prior to attending the screening visit.

\section{Study treatment}

Patients were randomized (2:1) to 2 years of open-label treatment with either GH (Norditropin SimpleXx, Novo Nordisk A/S, Copenhagen, Denmark) or to an untreated control group. GH was initiated at a starting dose of $0.2 \mathrm{mg} /$ day (males) and $0.4 \mathrm{mg} /$ day (females). The dose of $\mathrm{GH}$ was increased to 0.6 and $0.9 \mathrm{mg} /$ day in males and females respectively, at 1 month and was then raised again to $1.0 \mathrm{mg} /$ day (males) and $1.4 \mathrm{mg} /$ day (females) at 3 months for the remainder of the study. Higher GH doses are required in women than in men to achieve normal IGF-1 levels $(30,35)$. Dose reduction was allowed at the discretion of the investigator following the occurrence of GH-related side effects. GH was given as a single daily s.c. injection at bedtime using a cartridge pen (NordiPen, Novo Nordisk). Patients in the control group received no treatment during the study. The study was open and not placebo-controlled because it was deemed unethical to subject young adults to daily placebo injections for 24 months.

All patients attended the clinic at the screening visit (1-5 weeks before randomization), the randomization visit, and at months $1,3,6,12,18$, and 24. BMD of the lumbar spine (L1-L4), total body and total hip was assessed by dual energy X-ray absorptiometry (DEXA) at time of starting GH treatment and at months $6,12,18$, and 24. Hologic densitometers (Hologic QDR 4500, Hologic Inc.,Waltham, MA, USA) were used according to the protocol. Baseline and follow-up scans were performed on the same instrument for each patient. To control for possible differences between scanners at the different sites standardization procedures were carried out using a phantom (Hologic Spine Phantom) for 
calibration at all participating sites. DEXA data were transferred electronically for all readings to be performed centrally. Longitudinal stability of the scanners during the study was assessed from the DEXA spine phantom data which was reviewed monthly at the central site (Synarc Inc., Ballerup, Denmark) and corrective action was applied if necessary. Serum levels of alkaline phosphatase were determined using standard assay techniques. Serum levels of IGF-1 and IGFBP-3 were determined at a central laboratory with a solid-phase, enzyme-labeled chemiluminescent immunometric assay (Immulite 2000 IGF-1 and IGFBP-3; DPC) using an Immulite 2000 analyzer (Siemens Medical Services, Camberley, Surrey, UK). These assays each have an interassay variation of $6.8 \%$ in assay midrange. Intra-assay coefficient of variation was in accordance with the manufacturer's kit guidance. Agespecific reference ranges were used (median (central 95\% range); IGF-1, age 18 years, 308 (163-584) ng/ml; ages 21-25, 203 (116-358) ng/ml; IGFBP-3, age 18 years, $4.9(3.1-7.9) \mu \mathrm{g} / \mathrm{ml}$; ages $21-25$ years, $5.1(3.4-7.8) \mu \mathrm{g} / \mathrm{ml})$. Bone scans and biochemical samples were analyzed centrally at MDS Pharma Services Central Lab GmbH, Hamburg, Germany. Data from all efficacy and safety laboratory tests was sent electronically from MDS Pharma to the Contract Research Organization (Jellinggaard ApS, Eriksvej 2, DK-2600 Glostrup, Denmark) who performed the data management for the trial.

Safety was assessed by recording all patient- and investigator-reported treatment-emergent adverse events (AEs) during the study.

\section{Statistical analysis}

With a 5\% significance level and $80 \%$ power, it was estimated that 144 evaluable subjects were required to detect a minimum clinically significant change of $3 \%$ in BMD of the lumbar spine after 24 months. Assuming a dropout rate of $20 \%, 180$ subjects were planned to be enrolled in the study.

The primary efficacy endpoint, change in lumbar spine BMD during 24 months, was compared between study groups using an ANCOVA model with baseline BMD as covariate. Actual BMD measurements at baseline and at months 6, 12, 18, and 24 were evaluated in a repeated measure ANCOVA with treatment, visit, interaction between treatment and visit, country, age, and baseline BMD as covariates. The model contained a random subject effect. Secondary endpoints were analyzed in the same way as the primary endpoint. A 5\% significance level was used and all tests were two sided. For IGF-1 and IGFBP-3, SDS were calculated relative to laboratory reference values. Analyses were conducted on the intent-to-treat population which comprised all randomized subjects who received at least one dose of $\mathrm{GH}$ or who participated as an untreated control.

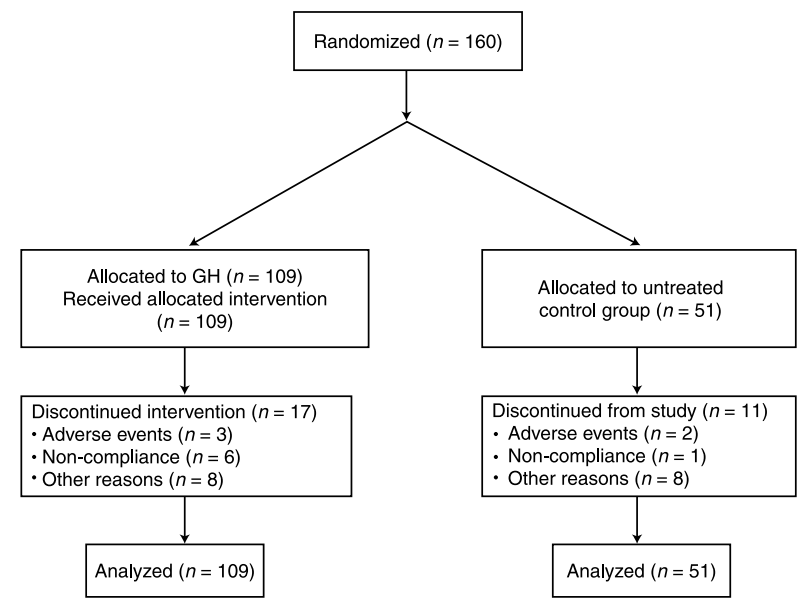

Figure 1 Study design.

\section{Results}

After informed consent, 160 patients $(\mathrm{GH}, n=109$; control, $n=51$ ) were randomized and all were included in the statistical analyses (Fig. 1).

Baseline demographic characteristics of patients, by study group, are summarized in Table 1 . No significant differences in baseline demographic characteristics were observed between groups. The number of patients in both treatment groups that had pituitary hormone deficiencies in addition to GHD and were receiving hormone replacement therapies is shown in Table 1.

Table 1 Baseline demographic characteristics of patients.

\begin{tabular}{|c|c|c|}
\hline & $\begin{array}{l}\text { GH } \\
(n=109)\end{array}$ & $\begin{array}{l}\text { Control } \\
(n=51)\end{array}$ \\
\hline Male:female (\%) & $60: 40$ & $67: 33$ \\
\hline Age (years) & $21.1(2.3)$ & $21.4(2.1)$ \\
\hline Height (cm) & $165.7(11)$ & $167.5(8.8)$ \\
\hline Weight (kg) & $63.5(15)$ & $65.4(13)$ \\
\hline $\operatorname{BMI}\left(\mathrm{kg} / \mathrm{m}^{2}\right)$ & $22.9(3.5)$ & $23.2(3.4)$ \\
\hline \multicolumn{3}{|l|}{ Pituitary hormone deficiencies } \\
\hline Panhypopituitarism & 3 & 3 \\
\hline Partial hypopituitarism & 1 & - \\
\hline $\begin{array}{l}\text { Hypogonadotrophic } \\
\text { hypogonadism }\end{array}$ & 1 & - \\
\hline Partial gonadotropin deficiency & 1 & - \\
\hline $\begin{array}{l}\text { Partial cortisol deficiency } \\
\text { Hormone replacement therapy }\end{array}$ & 1 & - \\
\hline Hydrocortisone & $\begin{array}{l}3 \text { ( }+1 \text { emergency } \\
\text { use only) }\end{array}$ & 3 \\
\hline Thyroxine & 3 & 3 \\
\hline DDAVP (desmopressin) & 2 & 1 \\
\hline Oestradiol & 1 & - \\
\hline Progestogen & 1 & - \\
\hline $\begin{array}{l}\text { Oral contraceptive pill } \\
\text { (as hormone } \\
\text { replacement) }\end{array}$ & 4 & 1 \\
\hline Testosterone & 1 & 2 \\
\hline
\end{tabular}

$\mathrm{BMI}$, body mass index; $\mathrm{GH}$, growth hormone. Note that patients may have more than one pituitary hormone deficiency and might receive more than one hormone replacement therapy. 


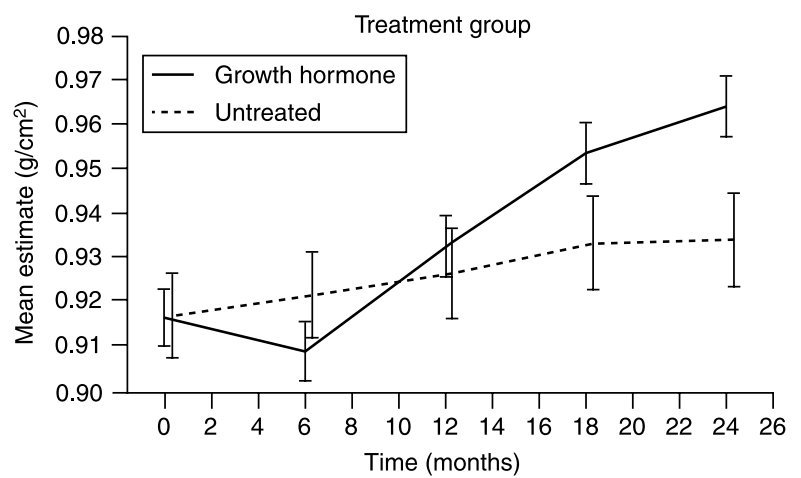

Figure 2 Change in dual energy $X$-ray absorptiometry-derived bone mineral density during the 24-month treatment period in GH-treated and untreated subjects. Data are shown as repeated mean estimates (estimated mean) with $95 \%$ confidence intervals.

The numbers of patients who completed the study period were $92 \mathrm{GH}$-treated and 40 control subjects. The reasons for discontinuation were mainly patient decision; only five patients withdrew due to AEs (GH group, Cushing's syndrome (recurrence), edema and papillary thyroid cancer; control group, increased weight (two patients), skin striae on the upper parts of both legs). Mean (s.D.) GH dose at the 24-month visit was $17.9(6.3) \mu \mathrm{g} / \mathrm{kg}$ per day.

\section{GH dose}

The median (min-max) GH dose at the 24-month visit was $1.0(0.6-1.4) \mathrm{mg} /$ day. Five patients required a reduction in $\mathrm{GH}$ dose. Dose reduction was in the range of $20-36 \%$ in each case and was done at either the 12- or 18-month visit.

\section{Efficacy}

The change in lumbar spine BMD from baseline during the 24-month study period is shown in Fig. 2. GH treatment was associated with a significantly greater increase in BMD from baseline to end of treatment compared with controls $(6.0$ vs $2.0 \%$, estimated treatment difference 3.5\%; 95\% confidence interval (CI) 1.5-5.5, P<0.001). As expected, a net loss in bone mass was observed during the initial 6 months of $\mathrm{GH}$ treatment, after which there was a net increase in bone mass (Fig. 2).

Table 2 summarizes changes from baseline in BMD of total hip (femoral neck, trochanter, and Ward's triangle) and total body. Compared with controls, the GH treatment effect was statistically significant for total hip BMD (treatment effect (GH-control), 95\% CI 2.43\% (95\% CI $0.48,4.43), P=0.015)$, but not for total body BMD $(0.51 \%(-0.49,1.53), P=0.315)$. As observed for the lumbar spine, BMD of the total hip and total body decreased during the first 6-12 months of GH treatment after which a net increase was reported.

\section{Markers of bone remodeling}

Mean ( \pm s.D.) baseline values for alkaline phosphatase were similar between treatment groups $(\mathrm{GH}, 73.4$ \pm 27.4 ; controls, $79.4 \pm 36.4$ ). During the first 6 months of GH treatment, there was an initial increase in alkaline phosphatase, which was followed by a decline over the next 18 months (Fig. 3). At 24 months, there was a statistically significant difference in mean alkaline phosphatase levels between $\mathrm{GH}$-treated patients and controls (estimated treatment difference, $12 \mathrm{IU} / \mathrm{l}$; 95\% CI 2.65-21.35; $P=0.012$ ).

Mean serum IGF-1 levels were not different between treatment groups at baseline (Table 3). In GH-treated patients, mean serum IGF-1 levels increased from baseline during the initial 6 months of treatment then remained approximately constant for the remainder of the treatment period. At 24 months, serum IGF-1 levels were significantly higher than in controls $(P<0.0001$; Table 3). Expressed as SDS, GH treatment was associated with a normalization of the IGF-1 SDS from $-2.25(1.38)$ at baseline to $1.39(3.85)$ at 24 months. In controls, the IGF-1 SDS remained below normal levels throughout the study (Table 3). Elevated IGF-1 values ( $>2$ SDS) were recorded in 16 patients in the GH treatment group (none in untreated controls) during the study accounting for 5\% (33/612) of all IGF-1 observations.

Mean IGFBP-3 levels also increased with GH treatment and were significantly higher in GH-treated patients than in controls at 24 months $(P<0.0001$; Table 3). Similarly, the IGFBP-3 SDS at 24 months had increased from below to within the normal range in GH-treated subjects, but not in controls (Table 3).

Table 2 Changes from baseline in bone mineral density (BMD) of the total hip and total body after 24 months of GH treatment and in untreated control subjects and analysis of covariance (ANCOVA) of the two groups using treatment and baseline level as covariate.

\begin{tabular}{|c|c|c|c|}
\hline & $\begin{array}{c}\text { GH } \\
(n=109)\end{array}$ & $\begin{array}{l}\text { Control } \\
(n=51)\end{array}$ & $\begin{array}{c}\text { GH versus } \\
\text { control } \\
(P \text { value })\end{array}$ \\
\hline \multicolumn{4}{|c|}{ Lumbar spine BMD $\left(\mathrm{g} / \mathrm{cm}^{2}\right)$} \\
\hline Baseline & $0.91(0.13)$ & $0.93(0.11)$ & \\
\hline 24 months & $0.96(0.14)$ & $0.94(0.11)$ & \\
\hline Change from baseline & $0.05(0.05)$ & $0.02(0.04)$ & $P=0.0006$ \\
\hline \multicolumn{4}{|l|}{ Total hip BMD $\left(\mathrm{g} / \mathrm{cm}^{2}\right)$} \\
\hline Baseline & $0.88(0.14)$ & $0.90(0.12)$ & \\
\hline 24 months & $0.90(0.14)$ & $0.89(0.12)$ & \\
\hline Change from baseline & $0.02(0.05)$ & $0(0.04)$ & $P=0.015$ \\
\hline \multicolumn{4}{|l|}{ Total body BMD $\left(\mathrm{g} / \mathrm{cm}^{2}\right)$} \\
\hline Baseline & $0.98(0.11)$ & $0.99(0.10)$ & \\
\hline 24 months & $1.00(0.12)$ & $1.00(0.09)$ & \\
\hline Change from baseline & $0.02(0.03)$ & $0.02(0.02)$ & $P=0.315$ \\
\hline
\end{tabular}




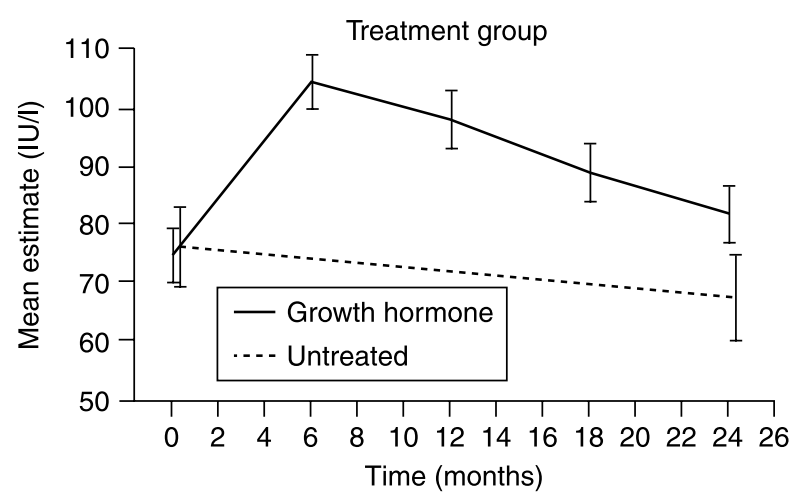

Figure 3 Change in serum alkaline phosphatase levels during the 24-month treatment period in $\mathrm{GH}$-treated and untreated subjects. Data are shown as repeated mean estimates (estimated mean) with $95 \%$ confidence intervals.

\section{Safety}

A total of 254 AEs were reported by 84 (53\%) patients. GH treatment was well tolerated and a similar proportion of patients on active treatment and controls experienced AEs ( 55 vs $47 \%$ ). The most common AEs were infections and head louse infestations which occurred in $29 \%$ of patients in the GH group and 35\% of untreated controls. AEs that were considered possibly or probably related to $\mathrm{GH}$ were reported by $13.8 \%$ of patients, the most common of which was edema (reported in $5.5 \%$ of patients). Serious AEs were reported by $6.4 \%$ of patients in the $\mathrm{GH}$ group and $5.9 \%$ in the untreated group. Two of these events in the GH group were considered by the investigator as possibly related to trial drug (hypertensive hydrocephalus after 6 months of GH treatment and recurrence of Cushing's syndrome in a patient with panhypopituitarism following neurosurgery for a hypophysis adenoma 4 years prior to entering the trial). The patient with hypertensive hydrocephalus temporarily discontinued treatment but reported no permanent cerebral damage.

\section{Discussion}

In this study, 24 months of treatment with GH in young adults with childhood-onset GHD was associated with a significant $(6 \% ; P<0.001)$ increase in BMD of the lumbar spine, as assessed by DEXA. This was accompanied by a significant $(2.4 \% ; P=0.015)$ increase in BMD of the total hip. No increase in total body BMD was detected in our study. Several recent studies have assessed the effects of $\mathrm{GH}$ replacement on BMD at completion of linear growth in children (36-39). Consistent with our findings, in a smaller study involving 24 adolescents with severe GHD, 12 months' GH therapy was associated with a $4.7 \%$ increase in mean lumbar spine BMD from baseline compared with a $2.7 \%$ change in those who discontinued treatment, while the median whole body BMC increased by $6 \%$ in GH-treated patients and remained unchanged in untreated patients (36). In another study in 149 postpubertal GH-deficient patients (mean age 19 years) who had terminated $\mathrm{GH}$ at adult height, significant increases in total BMC were observed in patients treated for 24 months with GH at a daily dose of $0.0125 \mathrm{mg} / \mathrm{kg}(9.5$ $\pm 8.4 \%)$ or $0.025 \mathrm{mg} / \mathrm{kg}(8.1 \pm 7.6 \%)$ compared with untreated controls $(5.6 \pm 8.4 \%$; ANCOVA, $P=0.008$ with no significant GH dose effect) (38). In that study, BMC increased predominantly at the lumbar spine

Table 3 Changes from baseline in insulin-like growth factor-1, insulin-like growth factor binding protein-3, insulin-like growth factor-1 SDS, and insulin-like growth factor binding protein-3 SDS after 24 months of GH treatment and in untreated control subjects and analysis of covariance (ANCOVA) of the two groups using treatment and baseline level as covariate.

\begin{tabular}{lccc}
\hline & $\begin{array}{c}\text { GH } \\
(n=109)\end{array}$ & $\begin{array}{c}\text { Control } \\
(n=51)\end{array}$ & $\begin{array}{c}\text { GH versus control } \\
(P \text { value })\end{array}$ \\
\hline $\begin{array}{l}\text { IGF-1 }(\mathrm{mg} / \mathrm{l}) \\
\text { Baseline }\end{array}$ & $132.9(128.1)$ & $165.2(163.5)$ & \\
24 months & $361.6(259.5)$ & $-21.9(52.3)$ & $P<0.0001$ \\
Change from baseline & $244.0(231.9)$ & $3.9(2.0)$ & \\
IGFBP-3 (mg/l) & $3.8(2.0)$ & $3.3(1.8)$ & \\
Baseline & $5.5(2.1)$ & $-0.1(0.9)$ & \\
24 months & $1.7(2.1)$ & $-2.4(-3.7$ to 3.7$)$ & \\
Change from baseline & $-2.7(-3.8$ to 4.5$)$ & $-2.5(-3.6$ to 3.8$)$ & \\
IGF-1 SDS & $0.4(-3.6$ to 12.06$)$ & $0.1(-1.9$ to 1.4$)$ & \\
Baseline & $3.4(-1.9$ to 13.4$)$ & $-1.1(-3.7$ to 2.2$)$ & \\
24 months & $-0.9(-4.5$ to 5.3$)$ & $-1.6(-3.8$ to 3.3$)$ & \\
Change from baseline & $0.8(-4.0$ to 5.8$)$ & $-0.1(-1.5$ to 3.1$)$ & $P<0.001$ \\
IGFBP-3 SDS & $1.5(-8.5$ to 6.9$)$ &
\end{tabular}

Data are mean (s.D.) for IGF-I and IGFBP-3 and median (range) for IGF-I SDS and IGFBP-3 SDS. GH, growth hormone; IGF, insulin-like growth factor; IGFBP, insulin-like growth factor binding protein; SDS, SD score. 
rather than at the femoral neck or head. Data from a meta-analysis of the relationship between BMD and fracture risk suggest that a 1 s.D. reduction in lumbar spine BMD is associated with an increase in relative risk for fracture at any site of $1.5 \%$ (95\% CI 1.4-1.7) (40). Hence, it has been suggested that $\mathrm{GH}$ treatment in post-pubertal young adults with childhood-onset GHD should be continued in the transition phase after linear growth is complete and until peak bone mass is achieved, with the aim of preventing osteopenia and the early incidence of osteoporosis and reducing the attendant risk of fracture due to bone fragility if peak bone mass is not achieved in early adulthood $(19,20)$.

The increase in BMD at the lumbar spine and total hip but not in total body BMD in our study, suggesting a decrease in BMD in some regions, is not unexpected given the different types of bone throughout the body. Histomorphometric studies (41) in normal subjects suggest structural differences at the cellular level between the axial and appendicular skeleton. The response of bone to GH may therefore be dependent on the type of bone, either cortical or trabecular, predominating at the site being assessed $(37,42)$. Longer follow-up may be required to assess the impact of continued GH therapy on whole body BMD. Nevertheless, the finding in our study that bone mass accretion with continued GH replacement beyond the achievement of adult height is particularly marked at the lumbar spine (38) is of considerable clinical impact given the vulnerability of this site to osteoporotic fractures in later life (43). Further studies may be warranted on the impact of GH therapy on osteoporosis and fracture incidence in this population.

Consistent with the results of this study, in a 10-year follow-up study in 23 childhood-onset GH-deficient men (mean age 29 years at treatment start), GH replacement was associated with a significant increase in BMD of the lumbar spine compared with baseline; a reduction in BMD was observed in control subjects (44). In the control subjects, BMD of the hip also decreased significantly compared with baseline whereas in GH-treated subjects, BMD in the hip was not significantly different from baseline values. It is known that peak bone mass is achieved during early adult life (at around the age of 30 years) and thereafter there is a slow decline in BMD with age. In the study reported by Arwert et al. (44), a natural decrease in BMD was apparent during 10 years of follow-up in controls but not in GH-treated patients.

In vitro studies have demonstrated that $\mathrm{GH}$ stimulates the proliferation of osteoblasts (45). GH also increases biomarkers of bone turnover in normal subjects (46) as well as adults (47) and children (21) with GHD. In the present study, DEXA measurements showed a net loss of BMD at the lumbar spine, total hip, and total body during the initial 6 months of treatment, followed by a steady increase in BMD at these sites. In the first months after GH therapy is begun, bone mineral resorption predominates over mineral disposition as more bone remodeling units are activated and the remodeling space is expanded, resulting in a net loss in BMD (48). This is subsequently reversed, leading to a progressive increment in BMD $(6,7)$. The observations of an initial net loss in BMD in the present study are consistent with findings from other studies. In 64 young adults who were treated with GH during childhood but had since discontinued GH treatment for at least 12 months, a dose-related decline in lumbar spine BMD was observed between baseline and month 6 after starting GH treatment, at a dose of 0.0125 or $0.025 \mathrm{mg} / \mathrm{kg}$ per day, that was followed by a dose-related increase to 24 months (31). At 24 months, the mean ( \pm s.D.) increase in BMD from baseline was 3.3 (3.9) and 5.2 $(4.7) \%$ in the 0.0125 and $0.025 \mathrm{mg} / \mathrm{kg}$ per day $\mathrm{GH}$ groups as compared with $1.3(2.8) \%$ in placebo-treated patients. Furthermore, in a comparison of the effects of long-term (36 months) and short-term (6-12 months) GH replacement therapy on BMD in patients with adultonset GHD, long-term GH therapy was associated with beneficial effects on BMD, particularly at the lumbar spine and trochanter (49). By contrast, the short course of GH therapy led to a decline in lumbar spine and Ward's area BMD while on treatment. Together, these observations suggest that beneficial effects of $\mathrm{GH}$ treatment on BMD may require at least a 9-10-month treatment period. Likewise, other studies have demonstrated no improvement in BMD with GH treatment although there has been an increase in terms of osteoid, mineralizing, and eroded surfaces without any change in adjusted apposition rate, mineral apposition rate, and bone formation rate consistent with a delay or lengthened remodeling period with a possible delay in mineralization (50-52). Furthermore, in vitro data indicate that while long-term $\mathrm{GH}$ appears to promote mineralization, short-term treatment does not promote proliferation of osteoblast precursors or induce expression of late osteogenic markers (53).

In our study, the bone turnover marker, alkaline phosphatase, was demonstrated to reflect the effectiveness of GH therapy. Alkaline phosphatase levels increased during GH treatment, peaking 6 months after initiation of treatment, consistent with an initial increase in bone resorption with GH therapy, and thereafter alkaline phosphatase declined towards pretreatment levels. Similar findings have been reported by other authors $(37,54)$. In GH-deficient children, Greig et al. (54) showed increased levels of alkaline phosphatase and osteocalcin during the first months of GH therapy that persisted for 24 months. In adult-onset GHD, alkaline phosphatase levels increased within 3 months of GH therapy then decreased at 12 months of therapy (55). A significant correlation between changes in serum levels of alkaline phosphatase and improvement in lumbar spine BMD has been demonstrated (56). It is noteworthy that Crippa et al. demonstrated an age-dependent influence of $\mathrm{GH}$ on 
alkaline phosphatase and alkaline phosphatase mRNA expression in cultured human osteoblastic cells, with the greatest effect observed in adolescents (13-16 year olds) followed by young adults (18-35 years) while the expression of evaluated genes was not affected by GH in cultures from adults (57).

The effect of GH on bone is mediated, at least in part, by IGF-1, and bone mass is known to be linked to circulating levels of IGF-1 (58). The present study shows that $\mathrm{GH}$ treatment was associated with a significant (twofold) increase in IGF-1 levels from baseline, resulting in a normalization of IGF-1 levels within the treatment period. A similar response to GH therapy has been reported in other GH treatment studies in young GHD adults with childhood onset disease $(28,31)$. As glucocorticoid replacement therapy was stable and adequate in patients included in this study, it is unlikely that substitution of corticotropic deficiency affected the observed GH response.

Moreover, in addition to the observed beneficial effects on BMD of continued GH treatment in patients with childhood-onset GHD patients after adult height has been achieved, continued lifelong therapy is also suggested to alleviate at least some of the aspects of the reduced physical and psychological health associated with GHD in adult life $(59,60)$. Severe quality of life (QoL) impairment is evident in a significant proportion of adults with GHD, and the beneficial effects of physiological GH replacement on QoL in affected individuals are well documented (61).

In conclusion, the results of this study support that continuation of GH therapy in the transition phase after completion of longitudinal growth may be necessary to allow patients with ongoing severe GHD to normalize peak bone mass. While the efficacy of $\mathrm{GH}$ in the prevention of fractures in $\mathrm{GH}$ deficient patients is not unequivocally documented, a protective action of GH on trabecular bone, in particular, may be evident. Further evaluation is warranted to establish the clinical benefit of this effect.

\section{Declaration of interest}

G S Conway has received honoraria from Pfizer for lecture fees; MS-C, $\mathrm{K}$ R, A K have nothing to declare; $\mathrm{P}$ Chanson has been an investigator in clinical trials sponsored by the pharmaceutical industry (Pfizer, Eli Lilly, Novo Nordisk, Serono), has received funds for organizing education, and is a member of the International Advisory Board of HypoCSS (Hypopituitary Control and Complication Study), which is sponsored by Eli Lilly; M Tauber has received honoraria for lecture fees: M Zacharin has nothing to declare.

\section{Funding}

This study received financial support from Novo Nordisk A/S.

\section{Acknowledgements}

This study was sponsored by Novo Nordisk A/S. The authors are grateful to the following investigators and study sites who participated in the study: Australia: Timothy Jones, Rob Johnston, Glynic Price, Subiaco; Martin Epstein, Newcastle; Margaret Zacharin, Fergus Cameron, Parkville; New Zealand: Ian Holdaway, Andrew Grey, Auckland; Belgium: Dominique Maiter, Brussels; Switzerland: RolfChristian Gaillard, Anna Maria De Luca, Guisti, Lausanne; Primus Mullis, Udo Meinhart, Sara Bachmann, Heinz Tschaeppeler, Kurt Lippuner, Rainer Wolf, Andreas Giger, Marianne Rohrbach, Jean-Marc Vuissoz, Bern; Germany: Eberhard Keller, Alexandra Keller, Leipzig; Spain: Antonio Carrascosa, Diego Yeste, Barcelona; France: Phillipe Chanson, Le Kremlin-Bicêtre; Thierry Brue, Marseille; Maïthé Tauber, Toulouse; UK: Gerry Conway, Alison Sturrock, London; John Connell, Faisel Ahmed, Glasgow; Hungary: Károly Rácz, Nokolette Szúcs, Győri Gabriella, Csaba Horváth, Ágnes Mondok, Miklós Góth, László Kovács, Erica Hubina, Budapest; Sweden: Gudmundur Johansson, Johan Svensson, Gothenburg; Poland: Tomasz Romer, Maria SzarrasCzapnik, Urszula Oczkowska, Warsaw; Jerzy Starzyk, Agata Górska, Dominika Januś, Anna Kalicka-Kasperczyk, Malgorzata KumorowiczKopiec, Aleksandra Górska, Katarzyna Doleżal-Oltarzewska, Dorota Roztoczańska, Joann Wojtyś, Edyta Piętkowska, Kraków; Barbara Krzyżanowska-Świniarska, Jaroslaw Ogonoswki, Tomasz Miazgowski, Szczecin; Maria Korpal-Szczyrska, Bohdana Dorant, Halina Kamińska, Dorota Birkholtz, Ludomira Rzepecka Wejs, Krystyna Turek, Gdańsk; Ewa Barg, Beata Wikiera, Diana Jędrzejczuk, Wroclaw, Norway: Jens Bollerslev, Oslo.

\section{References}

1 Kaufman J, Taelman P, Vermeulen A \& Vanderweghe M. Bone mineral status in growth hormone deficient males with isolated and multiple pituitary deficiencies of childhood onset. Journal of Clinical Endocrinology and Metabolism 1992 74 118-123.

2 de Boer H, Blok GJ, van Lingen A, Teule GJ, Lips P \& van der Veen EA. Consequences of childhood-onset growth hormone deficiency for adult bone mass. Journal of Bone and Mineral Research 19949 1319-1326.

3 Saggese G, Baroncelli G, Berttoni S \& Barasnati S. The effect of long-term growth hormone $(\mathrm{GH})$ treatment on bone mineral density in children with $\mathrm{GH}$ deficiency. Role of $\mathrm{GH}$ in the attainment of peak bone mass. Journal of Clinical Endocrinology and Metabolism 199681 3077-3083.

4 Degerblad M, Elgindy N, Hall K, Sjöberg HE \& Thorén M. Potent effect of recombinant growth hormone on bone mineral density and body composition in adults with panhypopituitarism. Acta Endocrinologica 1992126 387-393.

5 Holmes S, Economou G, Whitehouse R, Adams J \& Shalet S. Reduced bone mineral density in patients with adult-onset growth hormone deficiency. Journal of Clinical Endocrinology and Metabolism $1994 \mathbf{7 8}$ 669-674.

6 Johannsson G, Rosen T, Bosaeus I, Sjostrom L \& Bengtsson B. Two years of growth hormone $(\mathrm{GH})$ treatment increases bone mineral content in hypopituitary patients with adult-onset $\mathrm{GH}$ deficiency. Journal of Clinical Endocrinology and Metabolism $1996 \mathbf{8 1}$ 2865-2873.

7 Kann P, Piepkorn B, Schehler B, Andreas J, Lotz J, Prellwitz W \& Beyer J. Effect of long-term treatment with GH on bone metabolism, bone mineral density and bone elasticity in GH-deficient adults. Clinical Endocrinology 199848 561-568.

8 O'Halloran DJ, Tsatsoulis A, Whitehouse RW, Holmes SJ, Adams JE \& Shalet SM. Increased bone density after recombinant human growth hormone $(\mathrm{GH})$ therapy in adults with isolated $\mathrm{GH}$ deficiency. Journal of Clinical Endocrinology and Metabolism 1993 76 1344-1348.

9 Sartorio A, Ortolani S, Conti A, Cherubini R, Galbiati E \& Faglia G. Effects of recombinant growth hormone $(\mathrm{GH})$ treatment on bone mineral density and body composition in adults with childhood onset growth hormone deficiency. Journal of Endocrinological Investigation 199619 524-529. 
10 Murray R, Adams J \& Shalet S. A densitometric and morphometric analysis of the skeleton in adults with varying degrees of growth hormone deficiency. Journal of Clinical Endocrinology and Metabolism 200591 432-438.

11 Rosen T, Wilhelmsen L, Landin-Wilhelmsen K, Lappas G \& Bengtsson B. Increased fracture frequency in adult patients with hypopituitarism and growth hormone deficiency. European Journal of Endocrinology 1997137 240-245.

12 Wüster C, Abs R, Bengtsson BA, Bennmarker H, FeldtRasmussen U, Hernberg-Stahl E, Monson JP, Westberg B, Wilton P \& KIMS Study Group \& the KIMS International Board, Pharmacia \& Upjohn International Metabolic Database. The influence of growth hormone deficiency, growth hormone replacement therapy and other aspects of hypopituitarism on fracture rate and bone mineral density. Journal of Bone and Mineral Research $200116398-405$.

13 Ernst M \& Froesch ER. Growth hormone dependent stimulation of osteoblast-like cells in serum free cultures via local synthesis of insulin-like-growth factor-1. Biochemical and Biophysical Research Communications 1988151 142-147.

14 Slootweg MC, van Buul-Offers SC, Herrmann-Erlee MP, van der Meer JM \& Duursma SA. Growth hormone is mitogenic for fetal mouse osteoblasts but not for undifferentiated bone cells. Journal of Endocrinology 1988116 R11-R13.

15 Vandeweghe M, Taelman P \& Kaufman JM. Short and long-term effects of growth hormone treatment on bone turnover and bone mineral content in adult growth hormone-deficient males. Clinical Endocrinology 199339 409-415.

16 Zamboni G, Antoniazzi F, Radetti G, Musumeci C \& Tato L. Effects of two different regimens of recombinant human growth hormone therapy on the bone mineral density of patients with growth hormone deficiency. Journal of Pediatrics $1991119483-485$.

17 Baum HB, Biller BM, Finkelstein JS, Cannistraro KB, Oppenhein DS, Schoenfeld DA, Michel TH, Wittink H \& Klibanski A. Effects of physiologic growth hormone therapy on bone density and body composition in patients with adult-onset growth hormone deficiency. A randomized placebo controlled trial. Annals of Internal Medicine 1996125 883-890.

18 Davidson P, Milne R, Chase D \& Cooper C. Growth hormone replacement in adults and bone mineral density: a systematic review and meta-analysis. Clinical Endocrinology 200460 92-98.

19 Matkovic V, Jelic T, Wardlaw GM, Ilich JZ, Goel PK, Wright JK, Andon MB, Smith KT \& Heaney RP. Timing of peak bone mass in Caucasian females and its implications for the prevention of osteoporosis. Inference from a cross sectional model. Journal of Clinical Investigation 199493 799-808.

20 Bonjour JP, Theintz G, Buchs B, Slosman D \& Rizzoli R. Critical years and stages of puberty for spinal and femoral bone mass accumulation during adolescence. Journal of Clinical Endocrinology and Metabolism 199173 555-563.

21 Baroncelli G, Bertelloni S, Ceccarelli C, Cupelli D \& Saggese G. Dynamics of bone turnover in children with GH deficiency treated with GH until final height. European Journal of Endocrinology 2000 142 549-556.

22 Kroger H, Kotaniemi A, Kroger L \& Alhava E. Development of bone mass and bone density of the spine and femoral neck. A prospective study of 65 children and adolescents. Bone and Mineral 199323 171-182.

23 Sabatier JP, Guaydier-Souquières G, Laroche D, Benmalek A, Fournier L, Guillon-Metz F, Delavenne J \& Denis AY. Bone mineral acquisition during adolescence and early childhood: a study in 574 healthy females 10-24 years of age. Osteoporosis International 19966 141-148.

24 Attie KM. The importance of growth hormone replacement therapy for bone mass in young adults with growth hormone deficiency. Journal of Pediatric Endocrinology and Metabolism 2000 13 1011-1021.

25 Fors H, Bjarnason R, Wirent L, Albertsson-Wikland K, Bosaeust L, Bengtsson BA \& Johannsson G. Currently used growth-promoting treatment of children results in normal bone mass and density. A prospective trial of discontinuing growth hormone treatment in adolescents. Clinical Endocrinology 200155 617-624.

26 Attanasio AF, Howell S, Bates PC, Frewer P, Chipman J, Blum WF \& Shalet SM. Body composition, IGF-1 and IGFBP-3 concentrations as outcome measures in severely $\mathrm{GH}$-deficient (GHD) patients after childhood GH treatment: a comparison with adult onset GHD patients. Journal of Clinical Endocrinology and Metabolism 200287 3368-3372.

27 Attanasio AF, Lamberts SW, Matranga AM, Birkett MA, Bates PC, Valk NK, Hilsted J, Bengtsson BA \& Strasburger CJ. Adult growth hormone $(\mathrm{GH})$-deficient patients demonstrate heterogeneity between childhood onset and adult onset before and during human GH treatment. Adult Growth Hormone Deficiency Study Group. Journal of Clinical Endocrinology and Metabolism $1997 \mathbf{8 2}$ 82-88.

28 Koranyi J, Svensson J, Gotherstrom G, Sunnerhagen KS, Bengtsson B \& Johannsson G. Baseline characteristics and the effect of five years of GH replacement therapy in adults with $\mathrm{GH}$ deficiency of childhood or adult onset: a comparative, prospective study. Journal of Clinical Endocrinology and Metabolism 200186 4693-4699

29 Bachrach LK, Hastie T, Wang MC, Narasimhan B \& Marcus R. Bone mineral acquisition in healthy Asian, Hispanic, Black, and Caucasian youth: a longitudinal study. Journal of Clinical Endocrinology and Metabolism 199984 4702-4712.

30 Johannsson G, Albertsson-Wikland K \& Bengtsson BA. Discontinuation of growth hormone $(\mathrm{GH})$ treatment: metabolic effects in GH-deficient and GH-sufficient adolescent patients compared with control subjects. Swedish Study Group for Growth Hormone Treatment in Children. Journal of Clinical Endocrinology and Metabolism 199984 4516-4524.

31 Vahl N, Juul A, Jorgensen JO, Orskov H, Skakkebaek NE \& Christiansen JS. Continuation of growth hormone $(\mathrm{GH})$ replacement in $\mathrm{GH}$-deficient patients during transition from childhood to adulthood: a two-year placebo-controlled study. Journal of Clinical Endocrinology and Metabolism 200085 1874-1881.

32 Attanasio A \& Shalet S. Growth hormone and the transition from puberty into adulthood. Endocrinology and Metabolism Clinics of North America 200736 187-201.

33 Kaushal K \& Shalet SM. Defining growth hormone status in adults with hypopituitarism. Hormone Research 200768 185-194.

34 Growth Hormone Research Society. Consensus guidelines for the diagnosis and treatment of adults with growth hormone deficiency: summary statement of the Growth Hormone Research Society Workshop on Adult Growth Hormone Deficiency. Journal of Clinical Endocrinology and Metabolism 1998 83 379-381.

35 Burman P, Johansson AG, Siegbahn A, Vessby B \& Karlsson FA. Growth hormone (GH)-deficient men are more responsive to $\mathrm{GH}$ replacement therapy than women. Journal of Clinical Endocrinology and Metabolism $1997 \mathbf{8 2} 550-555$.

36 Drake WM, Carroll PV, Maher KT, Metcalfe KA, CamachoHubner C, Shaw NJ, Dunger DB, Cheetham TD, Savage MO \& Monson JP. The effect of cessation of growth hormone $(\mathrm{GH})$ therapy on bone mineral accretion in GH-deficient adolescents at the completion of linear growth. Journal of Clinical Endocrinology and Metabolism $2003 \mathbf{8 8} 1658-1663$.

37 Underwood LE, Attie KM \& Baptista J, Genentech Collaborative Study Group. Growth hormone $(\mathrm{GH})$ dose-response in young adults with childhood-onset GH deficiency: a two-year, multicenter, multiple-dose, placebo-controlled study. Journal of Clinical Endocrinology and Metabolism $2003 \mathbf{8 8} 5273-5280$.

38 Shalet SM, Shavrikova E, Cromer M, Child CJ, Keller E, Zapletalova J, Moshang T, Blum WF, Chipman JJ, Quigley CA \& Attanasio AF. Effect of growth hormone (GH) treatment on bone in postpubertal GH-deficient patients: a 2-year randomized, controlled, dose-ranging study. Journal of Clinical Endocrinology and Metabolism $2003 \mathbf{8 8} 4124-4129$.

39 Mauras N, Pescovitz OH, Allada V, Messig M, Wajnrajch MP \& Lippe B, Transition Study Group. Limited efficacy of growth hormone $(\mathrm{GH})$ during transition of $\mathrm{GH}$-deficient patients from 
adolescence to adulthood: a phase III multicenter, double-blind, randomized two-year trial. Journal of Clinical Endocrinology and Metabolism 200590 3946-3955.

40 Cummings R, Bates D \& Black DM. Clinical use of bone densitometry: scientific review. Journal of the American Medical Association $2002 \mathbf{2 8 8} 1889-1897$.

41 Schnitzler CM, Biddulph SL, Mesquita JM \& Gear KA. Bone structure and turnover in the distal radius and iliac crest: a histomorphometric study. Journal of Bone and Mineral Research 199611 1761-1768.

42 Attie KM. The importance of growth hormone replacement therapy for bone mass in young adults with growth hormone deficiency. Journal of Pediatric Endocrinology and Metabolism 2000 13 1011-1021.

43 Kanis JA. Assessment of fracture risk and its application to screening for postmenopausal osteoporosis: synopsis of a WHO report. WHO Study Group. Osteoporosis International 19944 368-381.

44 Arwert LI, Roos JC, Lips P, Twisk JW, Manoliu RA \& Drent ML. Effects of 10 years of growth hormone $(\mathrm{GH})$ replacement therapy in adult GH-deficient men. Clinical Endocrinology 200563 310-316.

45 Kassem M, Mosekilde L \& Eriksen EF. Growth hormone stimulates proliferation of normal human bone marrow stromal osteoblast precursor cells in vitro. Growth Regulation 1994 4 131-135.

46 Brixen K, Nielsen H, Mosekilde L \& Flyvbejerg A. A short course of recombinant growth hormone treatment stimulates osteoblasts and activates bone remodeling in normal human volunteers. Journal of Bone and Mineral Research 1990 5 609-618.

47 Hansen TB, Brixen K, Vahl N, Jorgensen JO, Christiansen JS, Mosekilde L \& Hagen C. Effects of 12 months growth hormone treatment on calciotropic hormones, calcium homeostasis, and bone metabolism in adults with acquired growth hormone deficiency: a double-blind, randomized placebo-controlled study. Journal of Clinical Endocrinology and Metabolism $1996 \mathbf{8 1}$ 3352-3359.

48 Andreassen TT \& Oxlund H. The effects of growth hormone on cortical and cancellous bone. Journal of Musculoskeletal and Neuronal Interactions 20012 49-58.

49 Rahim A, Holmes SJ, Adams JE \& Shalet SM. Long-term change in the bone mineral density of adults with adult onset growth hormone $(\mathrm{GH})$ deficiency in response to short or long-term $\mathrm{GH}$ replacement therapy. Clinical Endocrinology $1998 \mathbf{4 8} 463-469$.

50 Brixen K, Hansen TB, Hauge E, Vahl N, Jørgensen JO, Christiansen JS, Mosekilde L, Hagen C \& Melsen F. Growth hormone treatment in adults with adult-onset growth hormone deficiency increases iliac crest trabecular bone turnover: a 1-year, double-blind, randomized, placebo-controlled study. Journal of Bone and Mineral Research 200015 293-300.

51 Brixen K, Hansen TB, Eriksen EF \& Mosekilde L. Does growth hormone therapy in adult patients with growth hormone deficiency protect against bone loss? Growth Hormone and IGF Research 19988 81-86.
52 Marcus R. Recombinant human growth hormone as potential therapy for osteoporosis. Bailliere's Clinical Endocrinology and Metabolism 199812 251-260.

53 Haase HR, Ivanovski S, Waters MJ \& Bartold PM. Growth hormone regulates osteogenic marker mRNA expression in human periodontal fibroblasts and alveolar bone-derived cells. Journal of Periodontal Research 200338 366-374.

54 Greig F, Greenfield E, Prasad V, AvRushkin TW, Bastian W, Yasumura S \& Castells S. Increase in bone density and plasma osteocalcin during growth hormone therapy in growth hormone deficient children. Journal of Pediatric Endocrinology and Metabolism $19971011-17$.

55 Abrahamsen B, Hangaard J, Horn HC, Hansen TB, Gregersen G, Hansen-Nord M, Vahl N, Junker P, Andersen M \& Hagen C. Evaluation of the optimum dose of growth hormone $(\mathrm{GH})$ for restoring bone mass in adult-onset $\mathrm{GH}$ deficiency: results from two 12-month randomized studies. Clinical Endocrinology 200257 273-281.

56 Dresner-Pollak R, Mayer M \& Hochner-Celiniker D. The decrease in serum bone-specific alkaline phosphatase predicts bone mineral density response to hormone replacement therapy in early postmenopausal women. Calcified Tissue International $2000 \mathbf{6 6}$ 104-107.

57 Crippa GE, Beloti MM, Cardoso CR, Silva JS \& Rosa AL. Effect of growth hormone on in vitro osteogenesis and gene expression of human osteoblastic cells is donor-age-dependent. Journal of Cellular Biochemistry 2008104 369-376.

58 Yakar S, Rosen CJ, Beamer WG, Ackert-Bicknell CL, Wu Y, Liu JL, Ooi GT, Setser J, Frystyk J, Boisclair YR \& LeRoith D. Circulating levels of IGF-1 directly regulate bone growth and density. Journal of Clinical Investigation $2002 \mathbf{1 1 0} 771-781$.

59 Carroll PV, Drake WM, Maher KT, Metcalfe K, Shaw NJ, Dunger DB, Cheetham TD, Camacho-Hubner C, Savage MO \& Monson JP. Comparison of continuation or cessation of growth hormone therapy on body composition and metabolic status in adolescents with severe GH deficiency at completion of linear growth. Journal of Clinical Endocrinology and Metabolism 200489 3890-3895.

60 Prabhakar V \& Shalet S. Aetiology, diagnosis and management of hypopituitarism in adult life. Postgraduate Medical Journal 200682 259-266.

61 Woodhouse L, Mukherjee A, Shalet S \& Ezzat S. The influence of growth hormone status on physical impairments, functional limitations, and health-related quality of life in adults. Endocrine Reviews 200627 287-317.

Received 19 March 2009

Accepted 23 March 2009 